\title{
Perception of the importance of human-animal interactions on cattle flow and worker safety on Minnesota dairy farms
}

\author{
U. S. Sorge, ${ }^{1}$ C. Cherry, and J. B. Bender \\ University of Minnesota, Department of Veterinary Population Medicine, St. Paul 55108
}

\begin{abstract}
Proper cattle-handling techniques (stockmanship) are important to ensure calm animals and a safe work environment for dairy workers on farm. The objectives of this study were to (1) assess Minnesota dairy herd owners' attitudes toward stockmanship, its perceived importance for cow comfort and worker health, and the establishment of calm cattle movement; and (2) identify current resources and methods of stockmanship training on Minnesota dairy farms. A stratified-random sample of Minnesota dairy farmers were contacted via mail to participate in a 28-question survey. One hundred eight bovine dairy producers participated. Most commonly, respondents learned their cattle handling skills from family members $(42.6 \%)$ and $29.9 \%$ of producers had participated in previous stockmanship training. Producers thought that the skill of the human handler was the most important factor in establishing good cattle flow. Cattle-handling techniques was the third most common topic for new-employee orientation after training in milking parlor protocols and milking parlor disinfection. Time limitations and language barrier were considered serious challenges for worker training. Work-related injuries were responsible for lost work days in the previous year in $13.3 \%$ of dairy herds and $73.3 \%$ of those injuries occurred while working with cattle. Producers perceived that cattle-related injuries were predominantly the handler's fault: either because of not paying enough attention to the animal or due to poor cattle handling skills. Facility design was considered the least important for the occurrence of worker injuries. Although no causal inference can be made, herds that had workers who had previously participated in stockmanship training had a $810 \pm 378 \mathrm{~kg}$ (mean \pm standard error of the mean) higher rolling herd average than those that did not, even after adjusting for herd size and bulk tank somatic cell count. However, 50\% of respondents were not interested in attending future stockmanship training sessions. In conclusion, cattle
\end{abstract}

Received January 21, 2014.

Accepted March 31, 2014.

${ }^{1}$ Corresponding author: sorge@umn.edu handling skills are considered important by Minnesota dairy producers to ensure worker safety and cow flow. Limited availability of time, language barrier, and a perceived lack of training materials were considered challenges during the training of workers on farms.

Key words: cattle, stockmanship, handling, workrelated injury

\section{INTRODUCTION}

Dairy animals are handled on a daily basis. For example, cows are handled for health- or reproductionrelated management practices or moved from their freestall to the milking parlor for milking several times per day. During that time, cows will react to stimuli from the handler and environment. Timing, positioning, speed, and direction of movement as well as sounds made or touch by the handler will affect the behavior of the cow. Therefore, the handler needs to be aware of the body signals (s)he sends to calmly and successfully move cows. Unfortunately this is not always the case and the majority of nonfatal worker injuries on dairy farms are due to interactions with cattle (McCurdy and Carroll, 2000; Román-Muñiz et al., 2006). Every year, approximately 30 people die of cattle- and horse-related deaths in the United States (Langley and Morrow, 2010).

Improper handling techniques and the application of too much or inappropriate pressure also stress cattle. Stress has been shown to impair the production performance and health of cows. The former may include an increased time to move cows into the milking parlor and impaired milk letdown and, therefore, reduced production (Bruckmaier and Blum, 1998; Breuer et al., 2000; Hemsworth et al., 2000). In addition, stressed cattle are more likely to try to escape and can slip, injuring themselves. These injuries can be costly in terms of veterinary care and the increased possibility of culling injured cows. Stressed cattle can also affect the animal handlers; livestock-related injuries account for the highest rate of work days lost (Thu et al., 1997; Douphrate et al., 2009).

All of this affects the farm's performance not only through loss in milk production and possibly injured 
animals, but also lost work days and increased health care costs. Therefore, the proper handling of cows is of great importance for the dairy industry. Low-stress handling or stockmanship is not only crucial to ensure animal welfare and optimal production but also to promote worker safety (Breuer et al., 2000; Hemsworth, 2003).

Phillips et al. (2009) captured the perceived importance of stockmanship on animal welfare and health in a survey administered to producers associated with the Australian beef and small ruminant production (Phillips et al., 2009). For survey respondents, stockmanship was considered the most important factor to ensure animal welfare in beef cattle production. But the survey did not include questions about employee health, training, or herd production parameters.

In addition, limited information exists about employee training in cattle handling and also where or how producers as well as their employees learn the appropriate cattle handling techniques. If the latter are taught on a farm by their employer, what are potential challenges for the educators while teaching cattle handling and which methods are used? Furthermore, quantitative information is sparse about the effect of low-stress handling techniques on production and cattle welfare or which areas or daily tasks are considered challenges for cattle handling for dairy producers. Additionally, no data exist on whether dairy farmers are even interested in learning more about low-stress handling practices.

To address this knowledge gap of the perceived importance of stockmanship to dairy farmers, our survey had 2 primary objectives: to (1) assess Minnesota dairy herd owners' attitudes toward stockmanship and its perceived importance for cow comfort, worker health, and establishment of calm cattle movement; and (2) identify current training practices of stockmanship training on Minnesota dairy farms.

\section{MATERIALS AND METHODS}

\section{Survey Design}

A 4-page, 28-question anonymous survey was designed to collect stockmanship training history of dairy herd owners, cattle-handling approaches, challenging production areas, worker injuries, and herd and owner demographics. The questions included Likert-scale, ranking, and closed answer options. In addition to the paper version of the survey, participants could choose to complete an online version of the survey. The survey was pretested on 2 dairy farmers and 3 bovine veterinarians. The study protocol was reviewed and considered exempt by the University of Minnesota Institutional Review Board (St. Paul).
A list of all dairy herds in Minnesota $(\mathrm{n}=3,876)$ and their associated herd sizes was made available through the Minnesota Department of Agriculture. The list was split into 9 strata based on the herd size $(<50,50-99$, 100-149, 150-199, 200-249, 250-299; 300-399, 400-499, and $>500$ cows). From each stratum, 75 herds were randomly selected. However, the upper strata (herd size $\geq 300$ ) included very few herds and so all herds in those strata were contacted. The survey and a prepaid return envelope were sent to 620 producers twice, 1 mo apart.

\section{Statistical Analysis}

The data were analyzed in SAS (version 9.3; SAS Institute Inc., Cary, NC). The data were summarized with appropriate statistics, such as frequency statistics for categorical variables and median and 25th and 75th percentile or mean \pm standard error of the mean for continuous variables. The influence of previous stockmanship training on the rolling herd average was assessed with a general linear regression model (PROC GLM), which also included herd size (categorical) and bulk tank SCC (continuous) as fixed effects. Bulk tank SCC was forced into the model as it improved the fit of the model. Normality and homoscedasticity assumptions of the linear model were visually assessed. Associations between variables were analyzed using nonparametric statistics, such as the Fisher exact, Mann-Whitney U, or Kruskal-Wallis test. Missing values (i.e., unanswered questions) were not included in the final analysis. The significance level was set at $\alpha=0.05$.

\section{RESULTS}

One hundred ten dairy producers returned surveys, which included 2 dairy goat producers and 4 surveys that were filled out online. The responses of the 2 goat producers were excluded from the subsequent analysis.

The overall response rate was $17.3 \%$ and ranged between 11.0 and $25.4 \%$ for the herd size strata. A higher response rate was observed in herds milking over 200 cows. Most respondents were male $(73.6 \%)$, over 50 yr of age (60.4\%), and held either a college or university degree $(59.4 \%)$ or a high school diploma $(34.9 \%)$. Almost all farms had at least 2 employees or workers $(98.1 \%$; median $=6$; range $=1-35$; Table 1$)$.

Participants responded that they had learned cattle handling from a family member $(42.6 \%)$, through trial and error $(28.7 \%)$, or by observing cattle and people (18.5\%). In particular producers of smaller herds $(<100$ milking cows) had learned their animal handling skills from family members $(55.5 \%)$. None of the respondents said that watching videos had the greatest influence on how they moved or interacted with cattle (Table 2). 
Table 1. Herd demographics of respondents (unless otherwise stated, the mean $\pm \mathrm{SD}$ is reported)

\begin{tabular}{|c|c|c|c|c|c|}
\hline Item & \multicolumn{5}{|c|}{ Herd size (milking cows) } \\
\hline Respondents (no.) & 8 & 10 & 30 & 41 & 18 \\
\hline Response rate $(\%)$ & 11.0 & 13.3 & 20.4 & 16.7 & 25.4 \\
\hline No. of workers on farm [median (range)] & $2(1-5)$ & $3(2-5)$ & $5(2-6)$ & $9(4-20)$ & $17(10-35)$ \\
\hline Rolling herd average $(\mathrm{kg})$ & $6,997 \pm 3,260$ & $9,740 \pm 1,360$ & $10,340 \pm 1,988$ & $11,486 \pm 1,595$ & $12,925 \pm 948$ \\
\hline
\end{tabular}

Thirty-two participants $(29.9 \%)$ had previously attended dairy stockmanship training. The respondents from larger farms were more likely to have had stockmanship training than those with smaller herds. None of the producers with $<50$ milking cows completed a stockmanship course, whereas $36.6 \%$ of respondents with 200 to 499 milking cows and $50 \%$ of respondents with $\geq 500$ cows had at least 1 person on their farm who had attended a course $(P=0.03)$. Respondents were more likely to be interested in future stockmanship training if they had previously participated in such courses (odds ratio $=5.6 ; P<0.01$ ). The preferred methods of stockmanship training were on-farm training by an educator $(45.9 \%)$ or watching videos $(37.7 \%)$. However, almost half of the respondents (49.5\%) were not interested in receiving any formal stockmanship training in the future and $20.6 \%$ of participants were ambiguous to future learning opportunities in stockmanship.

Previous participation in stockmanship training was not associated with the bulk tank SCC. However, even after accounting for the herd size and bulk tank SCC, herds with workers with previous stockmanship training had, on average, an 810-kg ( $\mathrm{SEM}=378.8 \mathrm{~kg})$ higher average milk production per lactation per cow than those without previous stockmanship training $(P$ $=0.04 ;$ Table 3 ).

\section{Training of Workers}

On most farms $(53.9 \%)$ with employees $(\mathrm{n}=85)$, less than $50 \%$ of new employees had more than 6 mo of cattle experience when they started working on that farm. However, in this study, the retention time of employees on farms was not associated with the extent of previous cattle experience $(P>0.11)$, herd size $(P>0.65)$, or whether training was offered $(P=0.11)$. Interestingly, some farms $(25.5 \%)$ did not provide any training to new employees (Table 4). However, those herds were predominantly small herds ( $<50$ cows milking) without outside employees. Herds that offered training ( $\mathrm{n}=$ 79) most commonly offered training to new employees about milking procedures (91.1\%), cleaning and disinfectant protocols for the milking parlor $(88.6 \%)$, and handling techniques for cattle $(82.3 \%$, Table 4$)$.

The herd owner was the main instructor to employees on most farms (68.3\%). Training often included daily on-the-job training (11.5\%) and occurred as often as needed (55.3\%). Time limitations $(39.4 \%)$ and language barrier $(26.0 \%)$ were perceived as the main challenges during cattle handling training with employees. While on large farms, language barrier was increasingly cited as a challenge in training employees on how to work with cattle $(P<0.02)$; owners of small farms cited their own discomfort with teaching as the main challenge. Three producers specifically stated that training workers was difficult, because they were family members. Other specifically mentioned training challenges included "lack of animal instincts of employees" $(n=1)$, "lack of previous cattle experience" $(\mathrm{n}=1)$, "usually do not let employees move cattle" $(\mathrm{n}=1)$, "employees fear new techniques" $(\mathrm{n}=1)$, "employees who don't seem to understand" ( $\mathrm{n}=1)$, "personality of employee" $(\mathrm{n}=1)$, and "worker age and ethics" $(\mathrm{n}=1)$. Two owners saw no challenges during training.

\section{Cattle Handling}

The key areas with the most challenge for optimum cattle flow as identified by producers were milking fresh heifers $(37.0 \%)$, loading cattle into a treatment chute

Table 2. Greatest influence on how dairy farmers are moving and interacting with cattle $(\mathrm{n}=108)$

\begin{tabular}{lc}
\hline Greatest influence & $\begin{array}{c}\text { Dairy producer } \\
{[\text { no. }(\%)]}\end{array}$ \\
\hline Family member & $46(42.6)$ \\
Self-taught, trial and error & $31(28.7)$ \\
Observed cattle and people & $20(18.5)$ \\
Family member/self-taught & $4(3.7)$ \\
Attended seminar & $3(2.8)$ \\
Taught by employer, superior/farm manager & $2(1.9)$ \\
Other & $2(1.8)$ \\
Watched videos & 0 \\
\hline
\end{tabular}


Table 3. Association between milk production $(\mathrm{kg})$, previous stockmanship training, herd size, and bulk tank SCC based on a linear regression $\left(\mathrm{R}^{2}=0.43\right)$

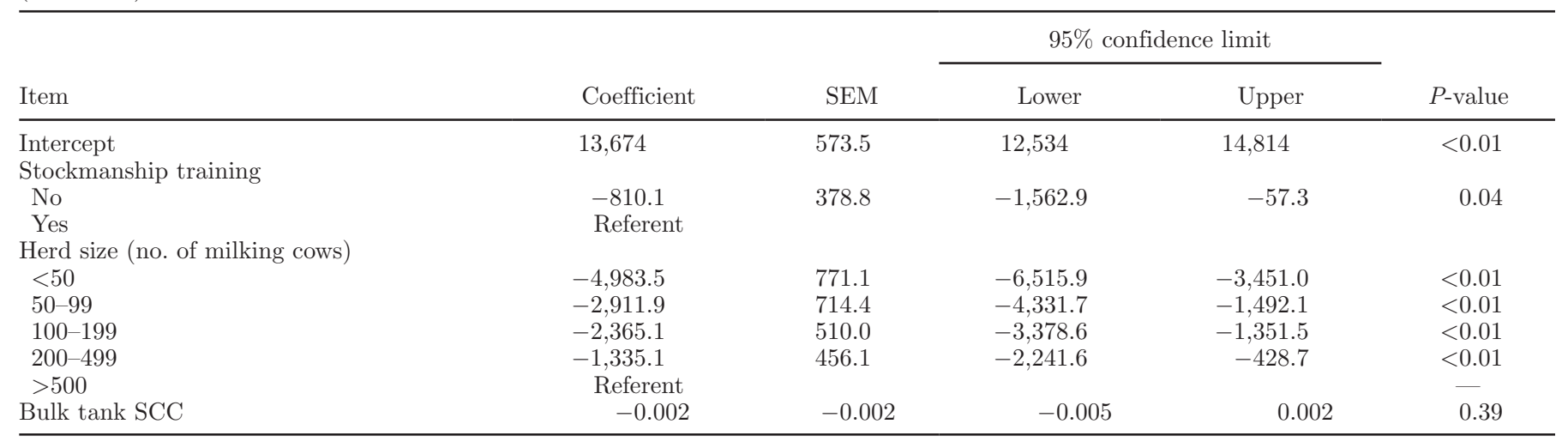

(22.4\%), loading cattle for transport (16.7\%), working with/moving calves (13.9\%), and loading the milking parlor (12.1\%; Table 5).

Some respondents $(15.7 \%)$ used a cattle prod when loading or unloading cattle for transport. Several producers $(\mathrm{n}=10)$ added written comments emphasizing the minimal use or absolute ban of cattle prods on their farm. Prod use was not associated with previous stockmanship training $(P=0.57)$, herd size $(P=0.21)$, age of the producer $(P=0.27)$, or education of the producer $(P=0.46)$.

The human handler was perceived as the most important factor for the establishment of good cattle flow by $62.1 \%$ of respondents (Figure 1). Other factors ranked in decreasing importance for cattle flow included the layout of facilities, the animals' behavior, and environmental factors (i.e., weather). Respondents (rank 1: $73.8 \%$ ) ranked facility design as most important factor for ensuring cow comfort compared with the influence of the handler (rank 1: 27.8\%) or environmental conditions (rank 1: 8.4\%).

\section{Worker Injuries}

On $13.3 \%$ of farms, workers had been injured in the previous calendar year (i.e., 2012) resulting in lost work days. The majority of these injuries $(73.3 \%)$ were reportedly due to cattle and 4 farms $(3.8 \%)$ even reported that cattle-related work injuries had resulted in higher insurance premiums in the previous 5 yr. In general, injuries were reported to occur more commonly in the milking parlor from cattle interactions than non-cattlerelated injuries that occurred in other areas of the farm (Table 6). Some herd owners also reported injuries due to slips $(\mathrm{n}=1)$ or a needle stick $(\mathrm{n}=1)$.

The primary reasons for cattle-related injuries were seen as not paying attention to cows (rank 1: 23.7\%; rank 2: $45.2 \%$ ) and poor cattle-handling skills (rank
1: $27.7 \%$; rank 2: $21.3 \%$ ). In general, producers were divided regarding their assessment of the predictability of cattle-related injuries and approximately the same percentage of respondents perceived them unavoidable $(32.3 \%)$ or avoidable $(27.9 \%)$. Compared with those without stockmanship training, producers with previous stockmanship training ranked the unpredictability of cows (rank 3: 33.3\%; rank 4: 44.4\%) and the overall unpredictability of cattle-related accidents $(P \leq 0.01)$ lower as a factor for injuries. Facility design was the least important factor for cattle-related injuries for most respondents.

\section{DISCUSSION}

Low-stress handling and stockmanship training has increasingly become an area of interest to livestock farmers in the United States. We tried to assess dairy producer perceptions of stockmanship and its effect on cow comfort and worker health. Key points in our survey included the type of training Minnesota producers had received or provided, the perceived importance of animal-handling skills to establish a good cattle flow on farm, and the description of worker injuries potentially due to cattle-human interactions.

Not surprisingly the majority of dairy farmers learned their cattle handling skills from family members, especially producers with fewer than 50 milking cows. Producers from smaller dairy herds were also less likely to have attended a formal stockmanship training program. Also, 29\% of participants cited self-taught or trial and error as the primary way to learn cattle-handling techniques. This was similar to reports from Swedish dairy farmers who highly valued experience and practice for skill development in handling cattle (Lindahl et al., 2012). However, almost one-third of participants had previously attended stockmanship training and several respondents expressed the need for the development of 
Table 4. Training of farm workers on Minnesota dairy farms (missing: $\mathrm{n}=2$ )

\begin{tabular}{|c|c|c|c|}
\hline \multirow[b]{2}{*}{ Item } & \multicolumn{3}{|c|}{ Farms } \\
\hline & $\begin{array}{c}\text { All } \\
\text { (no.) }\end{array}$ & $\begin{array}{l}\text { All } \\
(\%)\end{array}$ & $\begin{array}{l}\text { Only farms with } \\
\text { training }(\% ; \mathrm{n}=79)\end{array}$ \\
\hline \multicolumn{4}{|l|}{ Topics covered during training } \\
\hline Milking procedures & 74 & 69.8 & 91.1 \\
\hline Cleaning of milking parlor & 72 & 67.9 & 88.6 \\
\hline Handling techniques for cattle & 66 & 62.3 & 82.3 \\
\hline Operating machinery & 47 & 44.2 & 56.9 \\
\hline Handling/Feeding techniques for calves & 45 & 42.5 & 55.7 \\
\hline Safety training for machinery & 45 & 42.5 & 54.4 \\
\hline How to assess cow health & 44 & 41.5 & 54.4 \\
\hline Safety training for chemicals & 38 & 35.8 & 45.6 \\
\hline Treatment techniques & 36 & 33.9 & 44.3 \\
\hline Heat detection/breeding techniques & 36 & 33.9 & 44.3 \\
\hline No training & 27 & 25.5 & - \\
\hline \multicolumn{4}{|l|}{ Methods to train new employees } \\
\hline On-the-job training & 90 & 84.9 & 96.2 \\
\hline Lecture & 35 & 33.0 & 41.8 \\
\hline Written manual & 17 & 16.0 & 21.5 \\
\hline No training/NA ${ }^{1}$ & 14 & 13.2 & 1.3 \\
\hline Video & 14 & 13.2 & 17.7 \\
\hline Other & 3 & 2.8 & 3.8 \\
\hline \multicolumn{4}{|l|}{ Frequency of training offered } \\
\hline As needed & 58 & 55.3 & 60.7 \\
\hline Never & 16 & 15.2 & 3.8 \\
\hline Daily on the job & 12 & 11.4 & 12.7 \\
\hline Only as new employee & 8 & 7.7 & 8.8 \\
\hline$\geq$ Every 6 mo & 6 & 5.5 & 7.6 \\
\hline Other & 3 & 2.8 & 5.1 \\
\hline Annually & 1 & 1 & 1.3 \\
\hline \multicolumn{4}{|l|}{ Who trains the majority of employees } \\
\hline Herd owner & 71 & 68.3 & 67.0 \\
\hline Area manager & 20 & 19.2 & 24.1 \\
\hline Other employees & 9 & 8.7 & 8.9 \\
\hline Other & 4 & 3.9 & - \\
\hline \multicolumn{4}{|l|}{ Biggest challenge } \\
\hline Limited time & 38 & 39.6 & 40.0 \\
\hline Language barrier & 25 & 26.0 & 32.0 \\
\hline Other & 18 & 18.8 & 10.7 \\
\hline Own discomfort with teaching & 8 & 8.3 & 9.3 \\
\hline Lack of teaching materials & 7 & 7.3 & 8.0 \\
\hline
\end{tabular}

a broad range of educational materials in addition to supervised experiential learning on the farm.

Larger herds were twice as likely to respond to this study as small herds. This may be reflective of the gen- eral interest in learning low-stress handling techniques for workers with limited animal-handling knowledge and the potential liability and cost associated with worker injuries on larger operations. Smaller farm pro-

Table 5. Perceived degree of challenge to good cattle flow on key areas of dairy operations

\begin{tabular}{|c|c|c|c|c|c|}
\hline Key area on farm & \multicolumn{5}{|c|}{ Challenge level ( $\%$ of farms) } \\
\hline Getting cows from pen to parlor & 62.9 & 23.2 & 6.5 & 1 & 6.6 \\
\hline Milking fresh heifers for the first time & 6.5 & 55.6 & 29.6 & 7.4 & 0.9 \\
\hline Working with/moving calves & 42.6 & 41.7 & 12.9 & 1 & 1.9 \\
\hline Loading cattle for transport & 34.3 & 49.1 & 14.8 & 1.9 & - \\
\hline
\end{tabular}

\footnotetext{
${ }^{1}$ Not applicable.
} 
Table 6. Perceived frequency of injury occurrence in various areas on dairy farms

\begin{tabular}{|c|c|c|c|c|c|}
\hline Area of farm & \multicolumn{5}{|c|}{ Frequency of occurrence ( $\%$ of farms) } \\
\hline Injured by cattle while working in barn & 42.2 & 45.1 & 12.7 & - & - \\
\hline Other injury while working in parlor & 58.4 & 25.7 & 12.9 & 3.0 & - \\
\hline During field work & 73.5 & 23.5 & 3.0 & - & - \\
\hline Working around silos & 81.4 & 16.7 & 1.0 & 1.0 & 1.0 \\
\hline
\end{tabular}

ducers generally have family members as workers and cited the challenge of providing structured training to their workforce, because they were family members. This is supported by the fact that smaller farms often answered that no employees worked on the farm, even though they also reported that between 2 and 5 people worked on the farms.

Similar to the beef producers in an Australian study (Phillips et al., 2009) who perceived stockmanship as the most important factor to ensure animal welfare, the Minnesota dairy farmers valued stockmanship skills as an important factor for the establishment of good cow flow and very important for cow comfort on their operation. The survey demonstrated a perceived importance of stockmanship training, as facilities that provided training often included training of proper animal handling almost as often as proper milking routine and cleaning of the milking parlor. Cited challenges to conducting the employee training included time limitations and language barrier. With an increasing proportion of Hispanic workers on larger dairies in the
United States (Stack et al., 2006; Wilber et al., 2006; Baker and Chappelle, 2012), a need exists to reassess training materials and methods to reflect this changing workforce.

One interesting finding from this study was that, even after adjusting for herd size and bulk tank SCC, cows of producers who had participated in stockmanship training produced, on average, around $810 \mathrm{~kg}$ more milk per lactation than cows of producers who had not done stockmanship training. Phillips et al. (2009) had suggested that farmers are interested in good cattle-handling practices, because those practices will affect cattle "survival and productivity and are therefore economically important to farmers." Previous research has shown that stress negatively affects the milk production of cows (Breuer et al., 2000). Although a causal relationship between both factors cannot be inferred based on our survey data, one might speculate that participation in stockmanship training may be a surrogate factor for other management practices, such as routine training of employees, a positive attitude

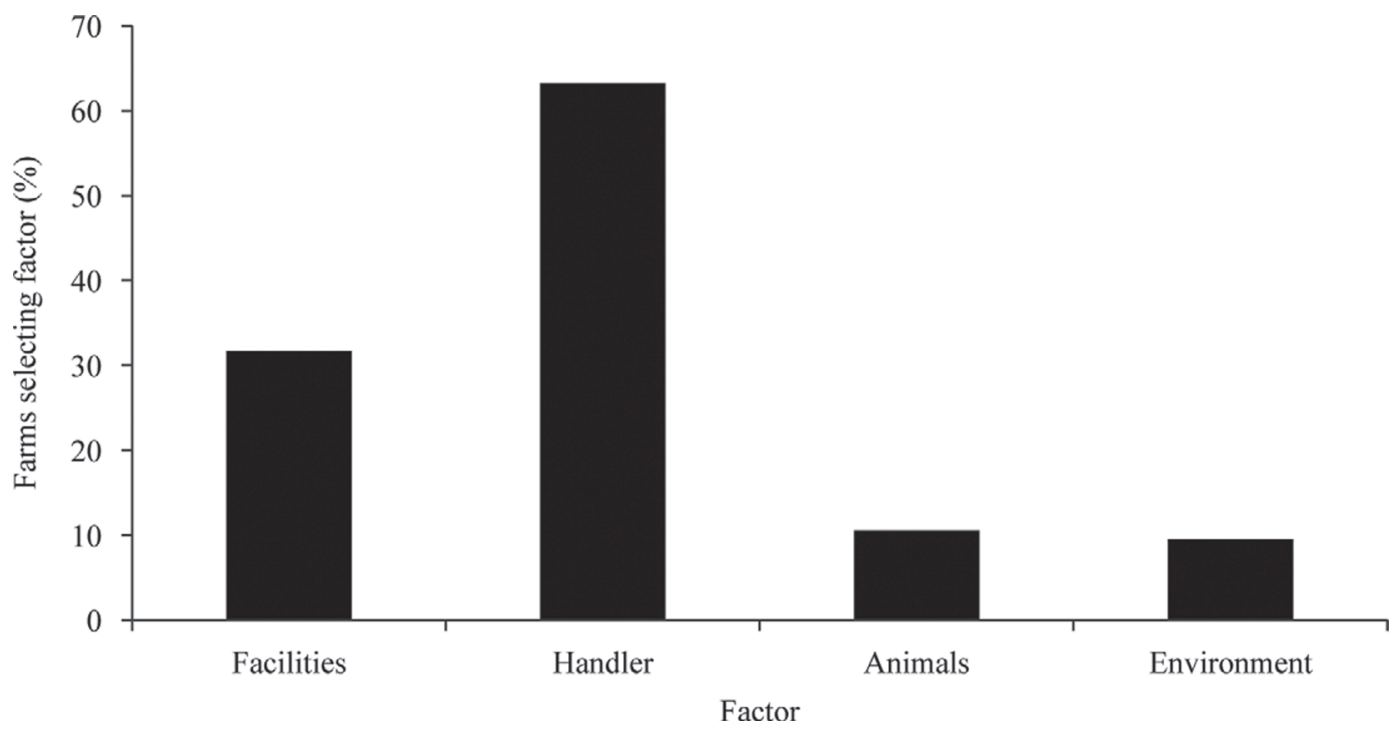

Figure 1. Perceived importance of factors for the establishment of cattle flow on dairy farms ( $\%$ of farms selecting factor as most important). 
toward employee and cow welfare, or general interest in/willingness to try novel approaches in dairy farming.

Good stockmanship skills were also perceived as important to prevent cattle-related worker injuries. Douphrate et al. (2009) reported that the majority of Occupational Safety and Health Administration (OSHA)-reported injuries that resulted in time off work were attributable to cattle-related incidences. Some of these cattle-related injuries even resulted in higher insurance premiums for dairy farmers in this study. Most producers thought that it was predominantly the handler's fault if cattle-related worker injuries occurred. The lack of cattle-handling skills or handler inattentiveness toward the animal were perceived as being of greater importance for the occurrence of these cattle-related accidents than facility design or the unpredictability of cattle. This finding was similar to that reported from Swedish dairy farmers (Lindahl et al., 2012). Furthermore, as reported in other studies (Boyle et al., 1997; McCurdy and Carroll, 2000; Román-Muñiz et al., 2006), the milking parlor and working with cows were considered the areas with the highest risk of injury on farms. Future training and research need to explore implementation of best practices to minimize risks in these areas.

Several limitations exist with this study. The first is the overall response rate. Likely, our study population may reflect responses from those individuals interested in dairy stockmanship and worker training. From this, caution is indicated in not over extrapolating the data on the relationship between stockmanship and production or injury prevention. However, our stratified random sample of dairy producers was an attempt to collect representatives from all strata of the Minnesota dairy industry. These preliminary findings do support the need for future studies to measure the impact of low-stress handling techniques or stockmanship on animal welfare, production, and prevention of worker injuries on dairy farms. Clearly, stockmanship skills are widely applicable across livestock industries and beyond Minnesota.

In conclusion, Minnesota dairy farmers perceived stockmanship skills as very important for cattle flow, cow comfort, and prevention of worker injuries. The majority of producers provided cattle handling training, but producers were faced with challenges of language barriers, time limitations, and easily accessible and applicable teaching material. Many producers are interested in stockmanship training. One challenge is to provide training to workers on small- to medium-sized dairies with few employees. These particular dairies likely face the most significant challenges, with busy work schedules and limited time and limited access to potential training opportunities. Future studies will need to identify effective teaching strategies for stockmanship to this diverse group of dairy farm employees to potentially reduce worker injuries and improve milk production on farm.

\section{REFERENCES}

Baker, D., and D. Chappelle. 2012. Health status and needs of Latino dairy farm workers in Vermont. J. Agromedicine 17:277-287.

Boyle, D., S. G. Gerberich, R. W. Gibson, G. Maldonado, R. A. Robinson, F. Martin, C. Renier, and H. Amandus. 1997. Injury from dairy cattle activities. Epidemiology 8:37-41.

Breuer, K., P. H. Hemsworth, J. L. Barnett, L. R. Matthews, and G. J. Coleman. 2000. Behavioural response to humans and the productivity of commercial dairy cows. Appl. Anim. Behav. Sci. 66:273-288.

Bruckmaier, R. M., and J. W. Blum. 1998. Oxytocin release and milk removal in ruminants. J. Dairy Sci. 81:939-949.

Douphrate, D. I., J. C. Rosecrance, L. Stallones, S. J. Reynolds, and D. P. Gilkey. 2009. Livestock-handling injuries in agriculture: An analysis of Colorado workers' compensation data. Am. J. Ind. Med. 52:391-407.

Hemsworth, P. H. 2003. Human-animal interactions in livestock production. Appl. Anim. Behav. Sci. 81:185-198.

Hemsworth, P. H., G. J. Coleman, J. L. Barnett, and S. Borg. 2000. Relationship between human-animal interactions and productivity of commercial dairy cows. J. Anim. Sci. 78:2821-2831.

Langley, R. L., and W. E. M. Morrow. 2010. Livestock handlingMinimizing worker injuries. J. Agromedicine 15:226-235.

Lindahl, C., P. Lundquist, and A. Lindahl Norberg. 2012. Swedish dairy farmers' perception of animal-related injuries. J. Agromedicine 17:364-376.

McCurdy, S. A., and D. J. Carroll. 2000. Agricultural injury. Am. J. Ind. Med. 38:463-480.

Phillips, C. J. C., J. Wojciechowska, J. Meng, and N. Cross. 2009. Perceptions of the importance of different welfare issues in livestock production. Animal 3:1152-1166.

Román-Muñiz, I. N., D. C. Van Metre, F. B. Garry, S. J. Reynolds, W. R. Wailes, and T. J. Keefe. 2006. Training methods and association with worker injury on Colorado dairies. J. Agromedicine 11:19-26.

Stack, S. G., P. L. Jenkins, C. Earle-Richardson, S. Ackerman, and J. J. May. 2006. Spanish-speaking dairy workers in New York, Pennsylvania, and Vermont: Results for a survey of farm owners. J. Agromedicine 11:37-44.

Thu, K., C. Zwerling, and K. Donham. 1997. Health problems and disease patterns. Livestock rearing. Pages $70-77$ in International Labor Encyclopedia of Occupational Health and Safety. 4th ed. J. Stellman, ed. International Labor Organization, Geneva, Switzerland.

Wilber, N., G. Hadley, G. Blonde and T. Anderson. 2006. Producer perceptions: Diverse workforce acceptance on Wisconsin dairy farms and farming communities - Shawano and Waupaca Counties. University of Wisconsin-River Falls, University of Wisconsin Extension, and Center for Dairy Profitability, Madison. 